\title{
Access to health care for older people with intellectual disability: a modelling study to explore the cost-effectiveness of health checks
}

\author{
Annette Bauer ${ }^{1 *} \mathbb{D}$, Laurence Taggart ${ }^{2}$, Jill Rasmussen ${ }^{3}$, Chris Hatton $^{4}$, Lesley Owen ${ }^{5}$ and Martin Knapp ${ }^{1}$
}

\begin{abstract}
Background: Whilst people with intellectual disability grow older, evidence has emerged internationally about the largely unmet health needs of this specific ageing population. Health checks have been implemented in some countries to address those health inequalities. Evaluations have focused on measuring process outcomes due to challenges measuring quality of life outcomes. In addition, the cost-effectiveness is currently unknown. As part of a national guideline for this population we sought to explore the likely cost-effectiveness of annual health checks in England.
\end{abstract}

Methods: Decision-analytical Markov modelling was used to estimate the cost-effectiveness of a strategy, in which health checks were provided for older people with intellectual disability, when compared with standard care. The approach we took was explorative. Individual models were developed for a selected range of health conditions, which had an expected high economic impact and for which sufficient evidence was available for the modelling. In each of the models, hypothetical cohorts were followed from $40 \mathrm{yrs}$. of age until death. The outcome measure was cost per quality-adjusted life-year (QALY) gained. Incremental cost-effectiveness ratios (ICER) were calculated. Costs were assessed from a health provider perspective and expressed in 2016 GBP. Costs and QALYs were discounted at 3.5\%. We carried out probabilistic sensitivity analysis. Data from published studies as well as expert opinion informed parameters.

Results: Health checks led to a mean QALY gain of 0.074 (95\% Cl 0.072 to 0.119$)$ ); and mean incremental costs of $£ 4787$ (CI 95\% 4773 to 5017). For a threshold of $£ 30,000$ per QALY, health checks were not cost-effective (mean ICER $£ 85,632 ; 95 \% \mathrm{Cl} 82,762$ to 131,944$)$. Costs of intervention needed to reduce from $£ 258$ to under $£ 100$ per year in order for health checks to be cost-effective.

Conclusion: Whilst findings need to be considered with caution as the model was exploratory in that it was based on assumptions to overcome evidence gaps, they suggest that the way health systems deliver care for vulnerable populations might need to be re-examined. The work was carried out as part of a national guideline and informed recommendations about system changes to achieve more equal health care provisions.

Keywords: Health checks, Assessment, Prevention, Early diagnosis, Ageing, Intellectual disability, Health inequalities, Cost-effectiveness, Decision-analytic modelling

\footnotetext{
* Correspondence: A.bauer@lse.ac.uk

${ }^{1}$ Personal Social Services Research Unit, London School of Economics and

Political Science, Houghton Street, London, England WC2A 2AE, UK

Full list of author information is available at the end of the article
}

(c) The Author(s). 2019 Open Access This article is distributed under the terms of the Creative Commons Attribution 4.0 International License (http://creativecommons.org/licenses/by/4.0/), which permits unrestricted use, distribution, and

reproduction in any medium, provided you give appropriate credit to the original author(s) and the source, provide a link to the Creative Commons license, and indicate if changes were made. The Creative Commons Public Domain Dedication waiver (http://creativecommons.org/publicdomain/zero/1.0/) applies to the data made available in this article, unless otherwise stated. 


\section{Background}

Older people with intellectual disability (ID) have more health conditions than people of a similar age in the general population, but many of these go undetected and untreated [1]. The higher morbidity has been explained by a combination of genetic and lifestyle factors, as well broader social determinants of health, which means that people are much more likely to experience pervasive disadvantage [1-4]; this includes active discrimination and other barriers people with ID face when accessing standard health services [5]. Whilst those factors play a role for all people with ID independently of their age, they accumulate over a person's lifetime and have a greater impact on quality of life as people age [59]. Health conditions typically associated with ageing in the general population often occur at a much earlier age, with higher prevalence and in combination [9-14]. There are substantial challenges of identifying health conditions early in this population due to 'diagnostic overshadowing', i.e. where physical and mental health symptoms are not only misattributed to the ID but also to age-related changes $[5,15]$. The consequences are delayed diagnosis and treatment [5, 7, 15-17]. As a result, their life expectancy at birth - although increasing - is 20 years lower than for people without ID [18-20].

Health checks for people with ID have been introduced in countries such as the United Kingdom, Canada and Australia to improve detection, treatment and prevention of new health conditions in this population [21, 22]. In England, health checks were introduced in 2008 in the form of a national scheme which incentivises general practices to offer checks to people registered as having an ID each year (which is why they are typically referred to as 'annual health checks') [23]. Staff from practices which opt into the scheme are required to undergo specialist training. This includes the use of templates such as the Cardiff Health Check, and more recently the National Electronic Health Check; the latter incorporates a wide range of questions about health conditions including ageing-related disorders, bowel and breast cancer screening and tests for osteoporosis. It also includes a section on mental health [24].

Evaluations of the national scheme found that annual health checks (AHCs) led to the identification of unmet health needs and unrecognised life-threatening conditions [21, 23]. However, those 'effectiveness' evaluations have focused on short-term process measures, such as the number of health checks attended, health assessments and investigations done and common health conditions diagnosed. One would expect that AHCs have an impact on health-related quality as well as on quantity of life because health conditions are identified and treated earlier on, or sometimes even prevented. However, robust evidence in this regard is still lacking. In addition, there is a gap in knowledge about the cost-effectiveness of AHCs [23].

The aim of this explorative economic study was to estimate impacts on long-term quality and quantity of life and costs of the AHC scheme for older people with ID in England. The work was carried out to inform a national guideline on this topic for the National Institute for Health and Care Excellence [25].

\section{Methods \\ Procedure}

We carried out an explorative cost-utility analysis comparing a strategy in which older people with ID were offered health checks every year in general practice (primary care) versus a strategy in which they received standard primary care. The first referred to care provided in general practices as part of the AHC scheme, whilst standard care referred to care provided by general practices not part of such scheme. We hypothesized that earlier identification of health conditions due to regular check-ups would lead to health improvements as well as potential reductions in costs due to fewer treatments for health conditions at a more severe stage. The analysis was explorative in nature and it was not the aim of the analysis to include all possible economic consequences of AHCs. Instead, the model focused on those health conditions that were covered by current checklists used in primary care and most important in terms of their (expected) economic impact. Decision-analytical Markov models were constructed to estimate lifetime quality-adjusted life years (QALYs) and costs from a National Health Service (NHS) perspective in 2016 prices, discounted at a standard annual rate of 3.5\% [26]. For each of a selected range of health conditions a separate Markov model was developed, generating the present values of lifetime cost and QALY gain linked to earlier identification or treatment of this particular health condition. We then aggregated the results of all single models in terms of their present values of lifetime costs and QALY gains. Double counting of overlapping health conditions was avoided by adjusting prevalence rates, or by only including those conditions that were expected to occur first. The net present value of the costs of yearly health checks was then added to those aggregated costs to derive a final incremental cost-effectiveness ratio (ICER). The modelling considered a hypothetical population aged 40 years (although for some health conditions older starting ages were applied), who were followed until death. The models were constructed using Microsoft Excel and applied half cycle corrections, probabilistic sensitivity analysis and Monte Carlo simulation to assess the impact of changes in parameters on the ICER.

The method is explained by describing the general approach that was applied across all models; where there 
was a deviation from this approach (for a particular health condition), this is highlighted. A technical report is available on NICE's website, which describes each single model for each health condition [27].

Sources from which data were taken to inform the modelling are referred to and described under respective sub sections. Data referred to population or clinical samples. For example, a large Irish cohort study was the primary source for probabilities that people developed health conditions. Probabilities for the identification of health conditions stemmed from data from a large primary care database in England. We used data from clinical studies to model the likely consequences of an earlier versus later identification of health conditions. Details of how the literature was searched for this study are provided in Additional file 1.

Figure 1 illustrates the key health states in our models and possible transitions between them during each cycle. Each year a person could develop a health condition, be identified with a health condition (or not), get treatment (or not), survive, or die (either because of the health condition or because of other causes). Of those people alive, they could live throughout each yearly cycle with or without a health condition, which was either treated or not. For some health conditions (high blood pressure, diabetes), a distinction was made whether a person's health condition was managed well (due to regular check-ups provided during AHCs) or just treated normally. Whether a person was identified with a health condition and received treatment for it (or whether the health condition was managed more closely rather than just treated normally) could influence the disease progression and yearly probability of death from the condition (if indicated by evidence). A quality of life weight (in the form of health utilities) and a cost were assigned to each event state (with death set equal to zero). We ran the models and calculated total costs and QALYs based on the time each person spent in each health state.

\section{Health conditions: selection, incidence and progression}

A selected number of ageing-relevant health conditions were included in our modelling: osteoporosis; breast cancer; bowel cancer; cataract; glaucoma; hearing problems; diabetes; hypertension. Coronary heart disease (CHD) and stroke were modeled as consequences of diabetes or hypertension; hip fracture was modeled as a consequence of osteoporosis. Not included due to a lack of economic evidence or because of expected low economic impact were: cervical cancer screening (smear test); prostate cancer; lung cancer; body mass index, cholesterol, weight; thyroid problems; arthritis; chronic obstructive pulmonary disease (COPD) and asthma; epilepsy; immunization status; mental health and dementia. The rationale for why health conditions were included or excluded is presented in Table 1 (and a more detailed explanation is provided in Additional file 1: Table S1).

Each health condition was modelled separately. For conditions known to interact with each other substantially (diabetes and hypertension), incidence rates were adjusted to avoid double-counting of costs and outcomes. For the same reason, conditions (such as heart diseases, stroke or hip fracture) typically preceded by conditions already covered in the modelling (hypertension, diabetes or osteoporosis in these cases) were not modelled separately. The model focused on the new occurrence (incidence) of conditions and did not consider conditions that existed before the person reached the age of 40 years (or respective starting ages). Data on the yearly incidence and progression of conditions were

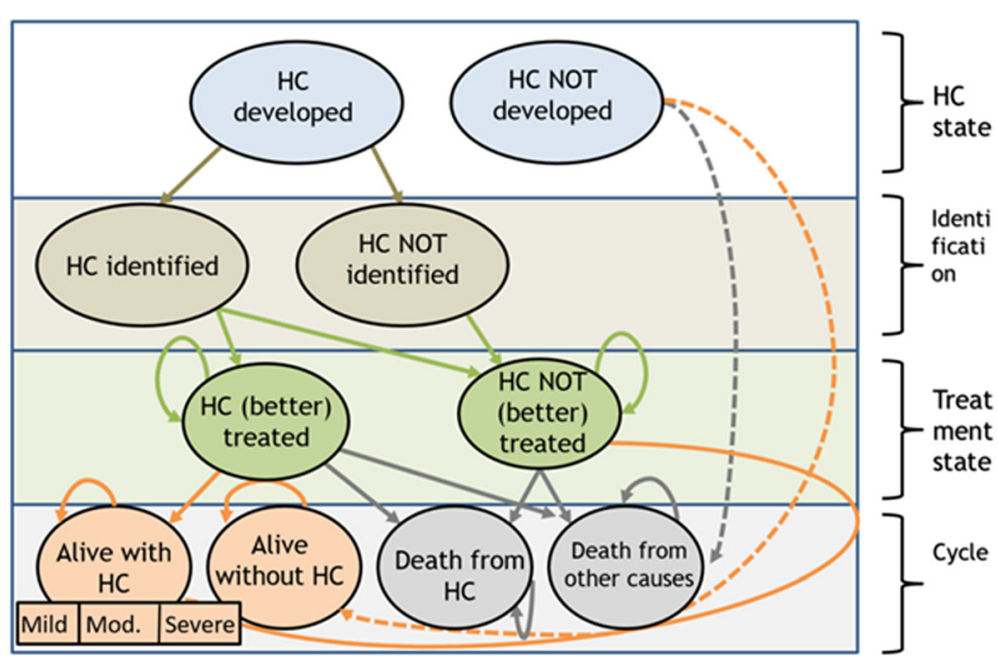

Fig. 1 Markov modelling, simplified transition-state-diagram ( $\mathrm{HC}=$ Health condition) 
Table 1 Rational for including or excluding health conditions

\begin{tabular}{|c|c|c|}
\hline Health condition & $\begin{array}{l}\text { Included/ } \\
\text { excluded }\end{array}$ & Rationale \\
\hline Arthritis & Excluded & $\begin{array}{l}\text { Despite a high prevalence, the expected impact on costs and outcomes was likely to be low or medium } \\
\text { due to uncertainties around optimal identification and management; in addition there was no } \\
\text { consistent evidence of whether AHC would improve the identification or management of arthritis. }\end{array}$ \\
\hline $\begin{array}{l}\text { High blood pressure } \\
\text { (hypertension) }\end{array}$ & Included & $\begin{array}{l}\text { The expected impact on costs and outcomes was high; robust (cost-) effectiveness evidence for blood } \\
\text { pressure management was available; evidence was also available that showed that AHC led to } \\
\text { improved identification and management of high blood pressure. }\end{array}$ \\
\hline $\begin{array}{l}\text { Body mass index, weight, } \\
\text { cholesterol }\end{array}$ & Excluded & $\begin{array}{l}\text { Overall, there was only limited evidence that AHC was able to influence those health promotion } \\
\text { outcomes. }\end{array}$ \\
\hline Bowel cancer screening & Included & $\begin{array}{l}\text { The expected impact on costs and outcomes was high because of a high prevalence of the condition, } \\
\text { the availability of a national screening programme, and the availability of (cost-) effective treatment; although } \\
\text { uptake has not been considered in the evaluations of AHCs there is evidence that additional information } \\
\text { provided by general practitioners increases uptake. }\end{array}$ \\
\hline
\end{tabular}

Breast cancer (screening via mammogram)

Included

The expected impact on costs and outcomes was high because of the high prevalence of the condition, the availability of a national screening programme, and of cost-effective treatment; although uptake has not been considered in the evaluations of AHCs there is evidence that additional information provided by general practitioners increases uptake.

Cataract

Included

Cervical cancer screening

Excluded

COPD and asthma

Excluded

Dementia

Excluded

Epilepsy

Excluded

Heart disease

Included (indirectly)

Hearing impairment

Included

Glaucoma

Included

Hip fracture

Included (indirectly)

Immunisation status

Excluded

Lung cancer/ smoking

Excluded

Mental health

Excluded

Osteoporosis (screening)

Included

Prostate cancer

Excluded

Stroke

Thyroid problems

The expected impact on costs and outcomes was high because of the high prevalence, availability of (cost-) effective treatment, and strong evidence that AHCs led to an increase in eye tests.

The expected impact on costs and outcomes was low because of the low prevalence in this population.

Evidence was insufficient: the prevalence of asthma was not well established for this population; there was no evidence that AHC would lead to changes in the identification or management of COPD or asthma.

Evidence was insufficient; in particular it was not clear whether dementia was currently checked in AHCs, and whether AHCs led to better identification.

Evidence was insufficient; in particular there was not enough robust evidence of cost-effective treatment.

Heart disease was modelled as a consequence of hypertension and diabetes, which were strong predictors of heart disease. Heart disease was not modelled separately to avoid double of counting economic consequences.

The expected impact on costs and outcomes was high due to the high prevalence and high impact for this population. There was robust evidence that AHC led to an increase in hearing tests; (cost-) effective treatment was available.

The expected impact on costs and outcomes was high; the impairment linked to glaucoma was and there was strong evidence that AHC led to more eye tests being carried out; (cost-) effective treatment was available.

This was modelled as a consequence of osteoporosis, which was a strong predictor fracture. Hip fracture was not modelled separately to avoid double counting of economic consequences. another incentivised scheme in primary care. This suggested a more limited role of AHCs in further improving uptake.

The expected impact on costs and outcomes was low due to lack of evidence of cost-effective treat ment options that would be influenced by an earlier identification; also lack of robust evidence whether identification improved through $\mathrm{AHC}$.

Evidence was insufficient; whilst prevalence data were available, there was no evidence about whether $\mathrm{AHC}$ led to a better identification of mental health problems; there was also a lack of evidence regarding (cost-) effective treatment options for this population.

The expected impact on costs and outcomes was high due the high prevalence and the availability of screening tools that led to an increase in the identification of osteoporosis and reduction in (costly) fractures. Screening for osteoporosis is covered by the new AHC tool in England.

Evidence was insufficient; prevalence data were not available and there was no robust evidence about (cost-) effective treatment options and whether AHCs led to increase in identification or improved management of the condition.

Included This was modelled as a consequence of hypertension and diabetes, which were strong predictors of (indirectly) stroke. Stroke was not modelled separately to avoid double counting economic consequences.

Excluded There is an overall lack of evidence suggesting that expected impact of identification or monitoring through annual health checks is likely to have a large impact on costs or health outcomes. 
derived from the Intellectual Disabilities Supplement to the Irish Longitudinal Study on Aging (IDS-TILDA) [17], with the exception of hearing problems, for which data were taken from two other sources because they were not available from IDS-TILDA [28, 29]. Parameters, their values, sources and descriptions are shown in Table 2.

\section{Populations: starting ages, gender and mortality}

Generally, a starting age of the cohorts of 40 years was used because this was consistent with that used by IDS-TILDA (and was considered appropriate by our experts due to the earlier onset of age-related conditions). However, for certain health conditions for which AHCs led to changes in screening uptake (breast and bowel cancer) or for which incidence rates increased strongly at a later age (osteoporosis), different starting ages were used according to the age from when screening was offered (or from which prevalence strongly increased) (Table 2). We calculated yearly age-specific transition probabilities from alive to dead using the National Life Tables for England [30]. Adjustments were made reflecting the three times higher mortality rate for people with ID [6]. For health conditions which could end in death (breast cancer, bowel cancer, diabetes, hypertension), additional calculations were carried out to derive yearly probabilities of death from those causes using national data sources [31-34].

\section{Uncertainty}

The impact of uncertainty around parameter values on the ICER was examined using probabilistic sensitivity analysis (PSA). In PSA, the full value range rather than a single value is considered for each parameter. This was done by determining the distributions that a value could take for each parameter and then running a large number (1000) of Monte Carlo simulations, which produced the results of different combinations of random draws. The choice of distributions followed the approach suggested by Sculpher [35]. In addition, one-way sensitivity analysis was applied for values that were particularly uncertain.

\section{Costs of the scheme}

The costs of health checks were estimated in consultation with experts from the Committee. They were asked to estimate the resource inputs required for delivering $\mathrm{AHC}$ according to best practice. Unit costs were then attached from national sources [36]. The relevant parameters, values, sources and details are shown in Table 3. Based on yearly costs we calculated the present value of total costs over a person's lifetime starting from 40 years of age.

\section{Cost consequences}

Unit costs were attached to the different states. This included the cost of participating in (additional) screening tests and other procedures for the diagnosis of health conditions or (immediate) follow-on treatment; in the case of breast cancer this included the cost of over-diagnosis due to additional screening procedures. Costs also included those for yearly treatment. Data for the unit cost of procedures or tests and cost for treating conditions were taken from recent national sources or economic evaluations [31, 40-49, 36-39]. In some instances $[38,41]$, cost estimates referred to present values of differences in life-time costs - in which case we directly assigned those cost differences to the additional risk that someone would be identified with the health condition (breast cancer) or would get monitored annually in the AHC group (diabetes). Parameters, value, sources and details are shown in Table 3.

\section{Effectiveness}

Effectiveness of AHCs referred to increased access to standard treatment as a result of changes in identification of health conditions or - in the case of diabetes and hypertension - to better management of those conditions due to regular check-ups. Thus, in each of the models, people in the AHC and standard care groups had different probabilities that their health conditions would be identified, or that their condition would be well managed (people receiving AHCs had a greater probability). For the two cancers covered in the modelling (bowel and breast cancers), this included data on increased screening uptake due to reminders provided during AHCs. Earlier identification and increased access to treatment (or better management of health conditions) were modelled reflecting - where indicated by evidence - lower probabilities of disease progression, progression into more severe disease, and of death.

Data on uptakes of AHC, identification rates for health conditions and better management of health conditions were taken from a large national evaluation [23], as well as from international evaluations of AHCs [50, 51], and from expert views. Data on access to treatments (including adherence to treatment) for those identified with a health condition were taken from national statistics and economic evaluations [31, 51-63]. Parameters, their values, sources and descriptions are shown in Table 4.

\section{Quality of life weights}

Quality of life weights (utilities) were attached to health states, which included different progression states for some conditions. Data on health utilities were taken from national (economic) evaluations and referred to the general population in England [37, 38, 41, 44-47, 62-66]. For some health conditions (diabetes and cataract), present 
Table 2 Parameter values (deterministic, in ranges) for modelling: Yearly probabilities for developing health conditions, and cohort starting ages

\begin{tabular}{|c|c|c|}
\hline & Data & Source and details \\
\hline \multicolumn{3}{|c|}{ Yearly probabilities for developing health conditions } \\
\hline \multicolumn{3}{|c|}{ Hypertension, diabetes excluded } \\
\hline 40 to 49 years & $\begin{array}{l}0.35 \text { to } \\
1.14 \%\end{array}$ & $\begin{array}{l}\text { Derived from } 3 \text { years incidence data } \\
\text { from IDS-TILDA by McCarron and col- } \\
\text { leagues [17] }\end{array}$ \\
\hline 50 to 64 years & $\begin{array}{l}1.56 \text { to } \\
2.28 \%\end{array}$ & As above \\
\hline 65 years+ & $\begin{array}{l}2.39 \text { to } \\
4.76 \%\end{array}$ & As above \\
\hline
\end{tabular}

Stroke

$\begin{array}{lll}40 \text { to } 49 \text { years } & \begin{array}{l}0 \text { to } \\ 1.11 \%\end{array} & \text { As above } \\ 50 \text { to 64 years } & \begin{array}{l}0.23 \text { to } \\ 1.13 \%\end{array} & \text { As above } \\ 65 \text { years+ } & 0.44 \text { to As above } \\ & 2.85 \%\end{array}$

Coronary heart disease (CHD)

$\begin{array}{lll}40 \text { to } 49 \text { years } & 0 & \text { As above } \\ 50 \text { to 64 years } & 0.07 \text { to } & \text { As above } \\ & 0.91 \% & \\ 65 \text { years+ } & 0.44 \text { to } & \text { As above } \\ & 2.82 \%\end{array}$

Diabetes

$\begin{array}{lll}40 \text { to } 49 \text { years } & \begin{array}{l}0 \text { to } \\ 1.11 \%\end{array} & \text { As above } \\ 50 \text { to 64 years } & \begin{array}{l}0.03 \text { to } \\ 1.32 \%\end{array} & \text { As above } \\ 65 \text { years }+ & 0.07 \text { to } & \text { As above }\end{array}$

Obesity

Proportion with $33.5 \% \quad$ As above obesity (all ages)

Bowel cancer 50 to 64 years

$\begin{array}{ll}65 \text { years }+ & 0.3 \text { to } \\ 2.49 \%\end{array}$

Breast cancer

$\begin{array}{lll}50 \text { to 64 years } & \begin{array}{l}0 \text { to } \\ 0.16 \%\end{array} & \begin{array}{l}\text { Derived from } 3 \text { years incidence data for } \\ \text { all types of cancer from IDS-TILDA by } \\ \text { McCarron and colleagues [17] applied to } \\ \text { proportion of breast cancer among all } \\ \text { types of cancer from Cancer Research } \\ \text { UK [30] }\end{array} \\ 65 \text { years + } & \begin{array}{ll}0.04 \text { to } \\ 0.19 \%\end{array} & \text { As above }\end{array}$

Osteoporosis
Table 2 Parameter values (deterministic, in ranges) for modelling: Yearly probabilities for developing health conditions, and cohort starting ages (Continued)

\begin{tabular}{|c|c|c|}
\hline & Data & Source and details \\
\hline 50 to 64 years & $\begin{array}{l}2.8 \text { to } \\
5.9 \%\end{array}$ & $\begin{array}{l}\text { Derived from } 3 \text { years incidence data } \\
\text { from IDS-TILDA by McCarron and col- } \\
\text { leagues [17] }\end{array}$ \\
\hline 65 years + & $\begin{array}{l}4.8 \text { to } \\
11.2 \%\end{array}$ & As above \\
\hline \multicolumn{3}{|l|}{ HIP fracture } \\
\hline 50 to 64 years & $\begin{array}{l}0.07 \text { to } \\
0.55 \%\end{array}$ & As above \\
\hline 65 years + & $\begin{array}{l}0.08 \text { to } \\
1.11 \%\end{array}$ & As above \\
\hline \multicolumn{3}{|l|}{ Cataract } \\
\hline 40 to 49 years & $\begin{array}{l}0.9 \text { to } \\
3 \%\end{array}$ & As above \\
\hline 50 to 64 years & $\begin{array}{l}1.32 \text { to } \\
3.2 \%\end{array}$ & As above \\
\hline 65 years + & $\begin{array}{l}1.04 \text { to } \\
4.09 \%\end{array}$ & As above \\
\hline
\end{tabular}

Glaucoma

\begin{tabular}{|c|c|c|}
\hline 40 to 49 years & $\begin{array}{l}0 \text { to } \\
1.2 \%\end{array}$ & As above \\
\hline 50 to 64 years & $\begin{array}{l}0.14 \text { to } \\
1.1 \%\end{array}$ & As above \\
\hline 65 years + & $\begin{array}{l}0 \text { to } \\
0.15 \%\end{array}$ & As above \\
\hline
\end{tabular}

Hearing problems

All ages 2 to Carvill [28] and Kerr and colleagues [29]

Cohort starting ages (if different from 40 years), years

\begin{tabular}{|c|c|c|}
\hline Bowel cancer & 60 & $\begin{array}{l}\text { Starting age of national screening } \\
\text { programme }\end{array}$ \\
\hline Breast cancer & 50 & As above \\
\hline Osteoporosis & 50 & $\begin{array}{l}\text { Age when prevalence strongly increases } \\
\text { according to data from IDS-TILDA by } \\
\text { McCarron and colleagues [17] }\end{array}$ \\
\hline
\end{tabular}

values of differences in QALY gains (or losses) linked to early identification or closer monitoring were already available in aggregated form from economic modelling studies, which included disease progression as relevant for the condition [41, 47]. For hearing impairment, only incremental values of health utility gain linked to ear-wax removal (a common problem in this population) and to hearing aid were available [61], and we thus assigned those to additional probabilities for people to benefit from AHC. Quality of life parameters, their values, sources and descriptions are shown in Table 5.

\section{Results}

Findings of the base case analysis are shown as averages per person (Table 6). AHCs led to a mean QALY gain of 
Table 3 Parameter values (deterministic, in ranges) for modelling: Cost inputs

\begin{tabular}{|c|c|c|}
\hline & Data & Source and details \\
\hline \multicolumn{3}{|l|}{ Cost inputs for annual health checks } \\
\hline General practice doctor & $£ 72$ & $\begin{array}{l}\text { PSSRU [36]; refers to } 20 \text { min of general practice doctor time with unit cost per hour of face-to- } \\
\text { face time of } £ 216 \text { (includes all administrative, preparation and follow-up costs, cost of home } \\
\text { visits) }\end{array}$ \\
\hline General practice nurse & $£ 43$ & PSSRU [36]; refers to $1 \mathrm{~h}$ of general practice nurse time with unit cost per hour of $£ 43$ \\
\hline Support worker & $£ 136$ & $\begin{array}{l}\text { Expert view; refers to } 8 \mathrm{~h} \text { of support worker time with unit cost per hour of face-to-face time } \\
\text { of } £ 17\end{array}$ \\
\hline Social worker & $£ 7$ & $\begin{array}{l}\text { PSSRU [36]; refers to } 5 \text { min of social worker time with unit cost per hour of client-related time } \\
\text { of } £ 79\end{array}$ \\
\hline \multicolumn{3}{|l|}{ Cost inputs for modelling hypertension } \\
\hline Diagnosis & $£ 29$ to $£ 89$ & Lovibond and colleagues [37] \\
\hline Hypertension management & $£ 34$ to $£ 102$ & As above \\
\hline Treating stroke (initially) & $\begin{array}{l}£ 5633 \text { to } \\
£ 16,901\end{array}$ & As above \\
\hline Subsequent treatment of stroke & $\begin{array}{l}£ 619 \text { to } \\
£ 1856\end{array}$ & As above \\
\hline $\begin{array}{l}\text { Treating coronary heart disease } \\
\text { (initially) }\end{array}$ & $\begin{array}{l}£ 1854 \text { to } \\
£ 5561\end{array}$ & $\begin{array}{l}\text { As above; includes costs of heart failure (£2929), angina ( } £ 3273) \text {, heart attack = myocardial } \\
\text { infarction, MI ( } £ 5455) \text {; weighted by their prevalence proportions from IDS-TILA by McCarron } \\
\text { and colleagues }[17] \text { in relation to all coronary heart disease conditions: heart failure }(51 \%) \text {, an- } \\
\text { gina }(21 \%), M I(28 \%)\end{array}$ \\
\hline $\begin{array}{l}\text { Subsequent treatment of coronary } \\
\text { heart disease }\end{array}$ & $\begin{array}{l}£ 143 \text { to } \\
£ 428\end{array}$ & $\begin{array}{l}\text { As above; includes costs of heart failure ( } £ 311) \text {, angina ( } £ 187) \text {, heart attack = myocardial } \\
\left.\text { infarction, MI ( } \_312\right) \text {; weighted by their prevalence proportions from IDS-TILA by McCarron } \\
\text { and colleagues [17] in relation to all coronary heart disease conditions: heart failure }(51 \%) \text {, an- } \\
\text { gina }(21 \%), \mathrm{MI}(28 \%)\end{array}$ \\
\hline
\end{tabular}

Cost inputs for modelling diabetes

$\triangle$ Controlled vs. uncontrolled $\quad-£ 618$ to glucose, non-overweight patients

$\triangle$ Controlled vs. uncontrolled glucose, overweight patients

Cost inputs for modelling bowel cancer (screening)

$\begin{array}{ll}\text { FOBT tests } & £ 16 \text { to } £ 19 \\ \text { Colonoscopy } & £ 469 \text { to } \\ & £ 573 \\ \text { Removing adenoma } & £ 122 \text { to } \\ & £ 149 \\ \text { Admittance for bleeding } & £ 712 \text { to } \\ & £ 870 \\ \text { Bowel cancer treatment detected } & £ 5971 \text { to } \\ \text { through screening } & £ 7298 \\ \text { Bowel cancer treatment clinically } & £ 7782 \text { to } \\ \text { detected } & £ 9511\end{array}$

Cost inputs for modelling breast cancer (screening)

$$
\begin{aligned}
& \text { Mammogram per woman invited for } \\
& \text { screening }
\end{aligned}
$$

Treating over-diagnosis

$$
\begin{aligned}
& \triangle \text { Treatment, early vs. late stage } \\
& \text { cancer, under } 65 \text { years (lifetime) }
\end{aligned}
$$

$\triangle$ Treatment, early vs. late stage cancer, over 65 years (lifetime)

$$
£ 14 \text { to } £ 36
$$$$
£ 2047 \text { to }
$$$$
£ 2501
$$

$-£ 11,739$ to $-£ 14,347$

$-£ 6404$ to $-£ 7827$

Cost inputs for modelling osteoporosis

DAX scan and General Practitioner (GP) consultation
Clarke and colleagues [38]; refers to present of total lifetimes costs; for non-overweight patients treated with insulin

As above; refers to present of total lifetimes costs; for overweight patients treated with metformin

Tappenden and colleagues [39]; refers to 2 FOBT tests (in case first is not returned)

National Schedule for Reference Costs 2015-16; refers to diagnostic colonoscopy [40]

As above

As above

Cancer Research UK [30]

As above

Pharoa and colleagues [31]

As above

Laudicella and colleagues [41]

As above

NICE $[41,43]$ 
Table 3 Parameter values (deterministic, in ranges) for modelling: Cost inputs (Continued)

\begin{tabular}{|c|c|c|}
\hline $\begin{array}{l}\text { Anti-osteoporotic medication (per } \\
\text { year) }\end{array}$ & $£ 54$ to $£ 334$ & $\begin{array}{l}\text { NICE }[41,43] \text {; refers to the most commonly prescribed drugs: alendronate, etidronate } \\
\text { risedrinate, raloxifene and strontium ranelate; and recommended doses }\end{array}$ \\
\hline $\begin{array}{l}\text { Treating hip replacement (HIP) } \\
\text { fracture, 1st year }\end{array}$ & $\begin{array}{l}£ 14,481 \text { to } \\
£ 14,800\end{array}$ & Leal and colleagues [44] \\
\hline Treating HIP fracture, 2nd year & $\begin{array}{l}£ 2160 \text { to } \\
£ 2272\end{array}$ & As above \\
\hline \multicolumn{3}{|l|}{ Cost inputs for modelling cataract } \\
\hline Initial optometrist test & $£ 21$ & $\mathrm{DH}[45]$ \\
\hline Optometrist diagnosis test & $£ 92$ to $£ 472$ & Burr and colleagues [46] \\
\hline Cataract surgery (lifetime) & $\begin{array}{l}£ 1218 \text { to } \\
£ 9211\end{array}$ & Frampton and colleagues [47] \\
\hline \multicolumn{3}{|l|}{ Cost inputs for modelling glaucoma } \\
\hline Initial optometrist test & $£ 21$ & $\mathrm{DH}[45]$ \\
\hline Optometrist diagnosis test & $£ 92$ to $£ 472$ & Burr and colleagues [46] \\
\hline Treating mild glaucoma (per year) & $\begin{array}{l}£ 259 \text { to } \\
£ 777\end{array}$ & As above \\
\hline $\begin{array}{l}\text { Treating moderate glaucoma (per } \\
\text { year) }\end{array}$ & $\begin{array}{l}£ 325 \text { to } \\
£ 875\end{array}$ & As above \\
\hline Treating severe glaucoma (per year) & $\begin{array}{l}£ 232 \text { to } \\
£ 695\end{array}$ & As above \\
\hline Treating visual impairment (per year) & $\begin{array}{l}£ 721 \text { to } \\
£ 927\end{array}$ & As above \\
\hline \multicolumn{3}{|l|}{ Cost inputs for modelling hearing problems } \\
\hline Ear wax removal & $£ 36$ to $£ 44$ & Clegg and colleagues [48]; refers to primary care \\
\hline Hearing specialist assessment & $£ 46$ to $£ 68$ & NHS National Tariff 2017 to 2019 [49] \\
\hline Hearing aid assessment & $£ 48$ to $£ 58$ & As above \\
\hline Hearing aid, initial & $\begin{array}{l}£ 268 \text { to } \\
£ 370\end{array}$ & As above \\
\hline Hearing aid, follow on care & $£ 23$ to $£ 28$ & As above \\
\hline
\end{tabular}

0.074. The 95\% Confidence interval (CI) ranged from 0.072 to 0.119 . Mean incremental costs were $£ 4787$ with a CI $95 \%$ of 4773 to 5017 . The mean ICER was $£ 85,632$ (95\% CI 82,762 to 131,944$)$. The yearly cost of an AHC was $£ 258$ per person. For health service decision-makers in England an ICER of less than $£ 20,000$ (or in some circumstances less than $£ 30,000$ ) is assumed to indicate the cost-effectiveness of an intervention [42]. Thus, AHC could not be considered cost-effective.

Another way of presenting our findings, including the uncertainty surrounding them, is through a cost-effectiveness plane (Fig. 2). The graph shows the incremental effects (measured in QALYs) on the $\mathrm{x}$-axis and incremental costs on the $y$-axis. The dots represent the results of 1000 Monte Carlo simulations. As can be seen, only a few dots lie below the lines that represent the cost per QALY threshold for cost-effectiveness at $£ 20,000$. At a more generous threshold of $£ 30,000$ per QALY (which used to be and is still considered sometimes the upper range of a cost per QALY threshold), a few more dots lie under the line. However, the vast majority of dots are centred at incremental costs of $£ 5000$ and incremental QALY gains of less than 0.1, suggesting ICERs of above $£ 50,000$ and higher.

Findings from additional one-way sensitivity analysis showed that the cost of an AHC was the only parameter that substantially influenced the results and could turn the decision whether AHCs were cost-effective from a negative to a positive one. Findings in Table 7 show that if AHC could be provided at $£ 50$ per person per year then the probability of cost-effectiveness would be $70.1 \%$ $(88.6 \%)$ at a cost per QALY threshold of $£ 20,000$ (£30,000); if the costs of annual health checks were $£ 75$ per person per year the probability would be $37.1 \%$ (66.1\%); and at a cost of $£ 100$ per person per year they would no longer be cost-effective (that is, their probability of being cost-effective was less than $50 \%$ ).

\section{Discussion}

The aim of our study was to explore the likely cost-effectiveness of a strategy, in which AHC are incentivised for people with ID as they age versus a strategy in which standard care is provided. Modelling was used to address large evidence gaps in this area. This included 
Table 4 Parameter values (deterministic, in ranges) for modelling: Inputs for effectiveness (including data on identification, screening uptake, progression, further investigation and treatment)

\begin{tabular}{|c|c|c|}
\hline & Data & Source and details \\
\hline \multicolumn{3}{|c|}{$\begin{array}{l}\text { Effectiveness of annual health checks in terms of: identification; uptake of national screening; management of conditions (in probabilities, annual } \\
\text { health check vs. standard care group) }\end{array}$} \\
\hline Hypertension identified and managed & $\begin{array}{l}85 \text { to } 95 \cdot 3 \% \text { vs. } \\
71 \cdot 4 \text { to } 87.8 \%\end{array}$ & Buszewicz and colleagues [23] \\
\hline $\begin{array}{l}\text { Participation in bowel cancer screening (FOBT), difference } \\
\text { between AHC and standard care, in percentage points }\end{array}$ & 4.1 to $7.8 \%$ & Hewitson and colleagues [52] and expert views \\
\hline Participation in breast cancer screening (mammogram) & $\begin{array}{l}54 \cdot 3 \text { to } 59 \cdot 3 \% \text { vs. } \\
47 \text { to } 52 \%\end{array}$ & $\begin{array}{l}\text { Derived from IDS-TILDA by McCarron and colleagues [17], } \\
\text { Gardner and colleagues [53] and expert views }\end{array}$ \\
\hline $\begin{array}{l}\text { Diabetes managed (identification found similar in both } \\
\text { groups) }\end{array}$ & $\begin{array}{l}69.9 \%(\text { SD 34.2) vs. } \\
56.8 \%(\text { SD 29.4) }\end{array}$ & $\begin{array}{l}\text { Cooper and colleagues [16]; refers to proportion of people } \\
\text { whose health monitoring needs are met }\end{array}$ \\
\hline Osteoporosis investigated & $\begin{array}{l}85 \text { to } 95 \% \text { vs. } 66 \cdot 2 \\
\text { to } 86.8 \%\end{array}$ & Derived from Lennox and colleagues [49] and expert views \\
\hline $\begin{array}{l}\text { Person with eye problem (cataract or glaucoma) is referred to } \\
\text { eye exam }\end{array}$ & $\begin{array}{l}90 \% \text { vs. } 58.9 \%(S D \\
0.24)\end{array}$ & Derived from Buszewicz and colleagues [23] and expert views \\
\hline $\begin{array}{l}\text { Person with hearing problems is referred to hearing } \\
\text { assessment }\end{array}$ & $\begin{array}{l}90 \% \text { vs. } 27.6 \text { to } \\
33 \%\end{array}$ & As above \\
\hline
\end{tabular}

Effectiveness of: identification; uptake of national screening; management of conditions Relative Risk (RR) in stroke, CHD and death, managed versus unmanaged hypertension Stroke

$\begin{array}{lll}\begin{array}{l}40 \text { to } 59 \text { years } \\ 60 \text { years }+\end{array} & 0.61 \text { to } 0.65 & \begin{array}{l}\text { Moran and colleagues [52] } \\ \text { As above }\end{array} \\ \text { CHD } & 0.66 \text { to } 0.71 & \\ 40 \text { to } 59 \text { years } & 0.72 \text { to } 0.74 & \text { As above } \\ 60 \text { years }+ & 0.74 \text { to } 0.78 & \text { As above }\end{array}$

Death

$\begin{array}{lll}40 \text { to } 59 \text { years }+ & 0.83 \text { to } 0.89 & \text { As above } \\ 60 \text { years }+ & 0.91 \text { to } 0.92 & \text { As above } \\ \text { Increased risk of stroke in people with hypertension } & 3 \text { to } 5 & \text { Straus and colleagues [55] } \\ \text { Increased risk of CHD in people with hypertension } & 2 \text { to } 3 & \text { Padwal and colleagues [54] } \\ \text { Absolute risk reductions (in percentage points) in death for } & 1.01 \% & \text { Scholefield and colleagues [57] }\end{array}$

people participating in bowel screening

Progression probabilities for glaucoma, treatment vs. not in treatment

Progression from mild to moderate

$22 \%$ vs. $25 \%$

Progression from moderate to severe

$7 \%$ vs. $11 \%$

Progression from severe to visual impairment

$6 \%$ vs. $10 \%$

Relative risk reduction of death from breast cancer for women 0.73 to 0.89 invited for mammography

Probabilities for further investigations and treatment (after screening or diagnosis)

Hypertension

Adherence to management

$75 \%$ (in one-way SA: $50 \%)$

Bowel cancer

Screening positive and requiring further investigation

Visit at specialist clinic for further investigation if screening was positive

Bowel cancer if screening was positive

Pre-cancer polyps if screening was positive

Admission for bleeding due to further investigation

$\begin{array}{ll}1.84 \text { to } 2.1 \% & \text { Raine and colleagues [58] } \\ 74.7 \text { to } 91.3 \% & \text { Logan and colleagues [59] } \\ 9.09 \text { to } 11.11 \% & \text { As above } \\ 24.48 \text { to } 29.92 \% & \text { As above } \\ 0.39 \text { to } 0.48 \% & \text { Tappenden and colleagues [37] }\end{array}$


Table 4 Parameter values (deterministic, in ranges) for modelling: Inputs for effectiveness (including data on identification, screening uptake, progression, further investigation and treatment) (Continued)

\begin{tabular}{|c|c|c|}
\hline & Data & Source and details \\
\hline \multicolumn{3}{|l|}{ Osteoporosis } \\
\hline Prescription of drugs to person identified with osteoporosis & $99 \cdot 6 \%$ & $\begin{array}{l}\text { Presentation by Shepstone at National Osteoporosis } \\
\text { Conference 2016; [58] refers to findings from SCOOP study }\end{array}$ \\
\hline \multicolumn{3}{|l|}{ Cataract } \\
\hline Corrected with glasses if referred to eye exam & 50 to $67 \%$ & Lennox and colleagues [51] \\
\hline Surgery if referred to eye exam & 5 to $9 \%$ & Expert view \\
\hline \multicolumn{3}{|l|}{ Glaucoma } \\
\hline Adherence to treatment & 63.9 to $78.1 \%$ & $\begin{array}{l}\text { Okeke and colleagues [61]; mean of } 71 \% \text {, value range }+/- \\
10 \%\end{array}$ \\
\hline \multicolumn{3}{|l|}{ Hearing problems } \\
\hline $\begin{array}{l}\text { Hearing problem due to blocked ear wax (i.e. no referral } \\
\text { required) }\end{array}$ & $15 \cdot 7$ to $50 \%$ & Robertson and colleagues [20] and Clegg and colleagues [48] \\
\hline $\begin{array}{l}\text { Hearing problem not due to blocked ear wax and referral } \\
\text { made to specialist }\end{array}$ & 50 to $84.7 \%$ & Derived as residual from above \\
\hline Person referred to specialist assessment attends it & 80 to $90 \%$ & Expert view \\
\hline Person assessed by specialist as requiring hearing aid & $42 \cdot 2$ to $51 \cdot 6 \%$ & Lennox and colleagues [50] \\
\hline Person requiring hearing aid accepts and starts using it & $36 \cdot 8$ to $86 \%$ & Morris and colleauges [59] \\
\hline \multicolumn{3}{|l|}{ Breast cancer } \\
\hline Breast cancer identified through mammogram & 73.3 to $93.8 \%$ & Sinclair and colleagues [63] \\
\hline $\begin{array}{l}\text { Relative risk of over-diagnosis for women invited to } \\
\text { mammography }\end{array}$ & $1 \cdot 19$ & As above \\
\hline
\end{tabular}

utilising a wide range of data sets and consulting experts on parameters and values that informed the model. Findings from our study suggest that AHCs provided to older people with ID are unlikely to be cost-effective from a health service perspective. This conclusion was robust across many scenarios; the only scenario in which AHCs were cost-effective was when their annual cost was reduced to about one-third of their current cost (a figure estimated by experts in the field).

One strength of this study was that the potential cost-effectiveness of AHCs was examined using appropriate methods to take account of uncertainties [67]. Second, experts were consulted on the model structure, inclusion of health conditions and parameters that were uncertain. Third, conservative assumptions were made to reflect the realities of current practice in England. For example, the cost of an AHC included not only cost incurred by general practice but also the cost of additional support provided by support workers, which help people to: attend medical appointments; understand the nature and reasons of visits and tests and test results. Whilst not everyone will need this kind of support and support workers will be employed independently of whether they provide help with AHCs, it is a relevant opportunity cost since support workers' time could be otherwise spent on helping the individual with something else or helping another person. Fourth, the analysis was informed by data from two recent, large-scale studies on this topic, helping to fill some evidence gaps (namely incidence of health conditions for this population [17] and on effectiveness of AHCs at the national level [23]).

This exploratory study has limitations linked to the many gaps in evidence, including those of: health utility values; incidence rates for some health conditions; access rates to secondary care treatment; and unit costs. Values for those parameters were taken from studies that referred to the general population; it is possible that they are different for people with ID. For example, there is currently not much knowledge about the validity of generic health-related quality of life measures such as the EQ-5D for this population, which is the measure used to derive health utilities [68, 69]. Whilst the experts we consulted thought that health utilities for this population were lower than in the general population due to the pervasive disadvantage and discrimination they experienced, no evidence could be identified to inform such values. However, this is unlikely to have influenced our incremental or net findings substantially since utilities would apply to all health states and would not change incremental QALYs, which are calculated in relative terms. A number of important health conditions could not be included in the modelling either because their incidence was not known from IDS-TILDA (e.g. asthma, chronic 
Table 5 Parameter values (deterministic, in ranges) for modelling: Quality of life weights (health utilities), $\Delta$ health utilities and $\triangle$ QALYS

\begin{tabular}{|c|c|c|}
\hline & Data & Source and details \\
\hline \multicolumn{3}{|c|}{ Health utilities (including $\triangle$ ) and QALYS } \\
\hline Stroke & $\begin{array}{l}0.31 \text { to } \\
0.94\end{array}$ & Lovibond and colleagues [37] \\
\hline Coronary heart disease & $\begin{array}{l}0.55 \text { to } \\
0.79\end{array}$ & $\begin{array}{l}\text { Derived from Lovibond and } \\
\text { colleagues [37] and Dyer and } \\
\text { colleagues [64]; weighted } \\
\text { average of health utility values } \\
\text { for heart failure }(0.645) \text {, angina } \\
\text { (0.77) and } \mathrm{Ml}(0.76) \text {; weighted } \\
\text { with their proportions of CHD } \\
\text { (as above) }\end{array}$ \\
\hline $\begin{array}{l}\text { Hypertension (without } \\
\text { cardiovascular event) }\end{array}$ & $\begin{array}{l}0.704 \text { to } \\
0.909\end{array}$ & $\begin{array}{l}\text { Lovibond and colleagues [37]; } \\
\text { refers to general population } \\
\text { health utilities from Health } \\
\text { Survey England data }\end{array}$ \\
\hline Bowel cancer & $\begin{array}{l}0.697 \\
(+/-10 \%)\end{array}$ & Whyte and colleagues [65] \\
\hline $\begin{array}{l}\text { Bowel cancer stages } \\
\text { Duke's A, B, C,D }\end{array}$ & $\begin{array}{l}0.74 ; 0.70 ; \\
0.5 ; 0.25 \\
(+/-10 \%)\end{array}$ & $\begin{array}{l}\text { Tappenden and colleagues } \\
\text { [66] }\end{array}$ \\
\hline Breast cancer & $\begin{array}{l}0.627 \text { to } \\
0.767\end{array}$ & Whyte and colleagues [65] \\
\hline HIP fracture, 1st year & $\begin{array}{l}0.64 \text { to } \\
0.77\end{array}$ & \\
\hline $\begin{array}{l}\text { Without HIP fracture, } 50 \\
\text { to } 60 \text { years }\end{array}$ & $\begin{array}{l}0.6 \text { to } \\
0.85\end{array}$ & As above \\
\hline $\begin{array}{l}\text { Without HIP fracture, } 60 \\
\text { years }+\end{array}$ & $\begin{array}{l}0.55 \text { to } \\
0.82\end{array}$ & As above \\
\hline Glaucoma, mild & $\begin{array}{l}0.72 \text { to } \\
0.88\end{array}$ & Burr and colleagues [46] \\
\hline Glaucoma, moderate & $\begin{array}{l}0.67 \text { to } \\
0.82\end{array}$ & As above \\
\hline Glaucoma, severe & $\begin{array}{l}0.64 \text { to } \\
0.78\end{array}$ & As above \\
\hline $\begin{array}{l}\text { Health utility gain }(\Delta) \\
\text { from removed ear wax }\end{array}$ & $\begin{array}{l}0.0054 \text { to } \\
0.0066\end{array}$ & Morris and colleagues [62] \\
\hline $\begin{array}{l}\text { Health utility gain }(\Delta) \\
\text { from hearing aid }\end{array}$ & $\begin{array}{l}0.035 \text { to } \\
0.105\end{array}$ & NICE [41] \\
\hline $\begin{array}{l}\text { QALYs }(\Delta) \text {, controlled vs. } \\
\text { uncontrolled diabetes in } \\
\text { non-overweight patients }\end{array}$ & $\begin{array}{l}-0.07 \text { to } \\
0.22\end{array}$ & $\begin{array}{l}\text { Clarke and colleagues [38]; } \\
\text { refers to present value of } \\
\text { QALYs gained for intensive } \\
\text { vs. standard management }\end{array}$ \\
\hline $\begin{array}{l}\text { QALYs }(\Delta) \text {, controlled vs. } \\
\text { uncontrolled diabetes in } \\
\text { overweight patients }\end{array}$ & $\begin{array}{l}-0.04 \text { to } \\
0.48\end{array}$ & As above \\
\hline $\begin{array}{l}\text { QALY gain linked to } \\
\text { cataract surgery }\end{array}$ & $\begin{array}{l}0.084 \text { to } \\
0.963\end{array}$ & Frampton and colleagues [47] \\
\hline
\end{tabular}

obstructive pulmonary disease) or because there was a lack of data on the costs and outcomes of earlier identification or treatment (e.g. thyroid problems, epilepsy, arthritis). Especially for conditions like dementia and mental illness, more evidence is needed about how to best identify those conditions in this population and about the (cost-) effectiveness of treatment and support options. In addition, for the majority of health conditions no evidence was available on follow-on treatments in secondary care once health conditions have been identified as a result of AHCs.

The impact of decent additional support in secondary care on access is currently not known. This also includes a lack of knowledge about the cost of this kind of additional support. In addition to those limitations, we were also unable to include a potential impact of earlier identification and treatment of health conditions on care home admission. Decisions about whether a person with ID is admitted to a care home are strongly influenced by their deteriorating health [70]. However, a lack of data prevented us from considering this potential economic impact. Similarly, we were not able to consider the impact on carers. This refers to the costs linked to the time spent by carers for supporting the person with ID ahead of, during and after medical appointments. This includes their traveling time to get to health care facilities. This cost is likely to present a large cost component of the overall support for people with ID. Whether this cost is influenced through the introduction of AHCs is currently not known, and presents an area where research is needed.

Despite those limitations, our study is the first analysis of long-term costs and outcomes of health checks for people with ID. The need for economic evidence in this area has been highlighted previously [10, 16, 23]. Previous studies which evaluated the cost-effectiveness of AHCs have been small-scale, short-term or included only a limited range of costs $[16,71,72]$. Findings from those studies suggest that there might be some improvements in overall health or reductions in service use but those impacts did not reach significance. None of the studies included the additional support from a support or social worker in their costs of AHCs; as a result their cost estimates for the intervention were substantially lower than ours, and authors were more likely to conclude that health checks were likely to be cost-effective. None of those studies looked at the population of older people specifically. From the perspective of health service expenditure alone, this is an important population given the high rates of health and social care service utilisation in old age [73].

As longevity improves for people with ID, it is imperative to consider how to best support the complex needs of this population in order to make the most cost-effective use of resources. Our findings highlight some of the dilemmas that commissioners and strategic decision-makers face. For example, changing only one part of the system (here: the identification of health conditions in primary care) is not leading to health-related quality 
Table 6 Base-case analysis results (probabilistic) - cost effectiveness annual health checks (AHC) vs. standard care, all prices in $£$ 2015/16, per person

\begin{tabular}{llll}
\hline & Incremental costs & Incremental QALYS & Incremental cost-effectiveness ratio (ICER) \\
\hline Mean & $£ 4787.24$ & 0.0743 & $£ 85,631.95$ \\
Standard deviation & $£ 230.05$ & 0.0456 & $£ 46,312.30$ \\
95\% Confidence interval & $£ 4772.98$ to $£ 5017.29$ & 0.0715 to 0.119 & $£ 82,761.49 .90$ to $£ 131,944.25$ \\
\hline
\end{tabular}

of life improvements or reductions in mortality if people are not able to access and benefit from effective treatment options provided in other parts of the system (in particular in secondary care). In current practice, many hospitals fail to provide care that is consistently accessible to people with ID $[74-77,5]$. Similarly, national screening programmes are not provided in a way that they are accessible for people with ID [78-80]. The need for collaborative approaches and wider system change in order to reduce health inequalities for this population has been highlighted in a number of studies [77-82].

Our findings should also be considered in the context of health checks provided to the general population of older people. Health checks have now been introduced in England for the general population aged 40 to 75 years. Concerns have been raised about their value for money, and their ability to achieve more benefits than harms has been questioned [83, 84]. Those concerns stem from: gaps in evidence concerning effective interventions and best practice when test results are positive; difficulties in explaining to patients the pros and cons of intervening versus not intervening during early disease stages; and the challenge of achieving behaviour change within one or two visits. "Although the goal is improved health outcomes, the pathway is long and tenuous, with attrition at each point along the way" [83]. Many of these challenges are likely to apply as much if not more to older people with ID.

Legislation and guidance request that barriers for people with ID in accessing health services are removed and reasonable adjustments are made [85-87]. Therefore, ethical considerations need to inform resource allocation decisions alongside economic ones. In current practice AHC offered to people with ID are a main policy vehicle for promoting a more equal access to health services. Thus, removing them might be considered highly unethical.

Seeking to respond to those challenges, the national guideline of which this study was a part made a number of recommendations about the provision of AHCs [25]: In particular:

- AHCs should be followed by prompt referrals to specialist services as needed; information on followon actions should be recorded;

- Practitioners carrying out AHCs should inform people about available health services including national screening programmes;

The guideline also recommends further research into the (cost-) effectiveness of alternative models and approaches for identifying health conditions and increasing access to treatment. This includes the role of well man and women clinics. In addition, the guideline makes a

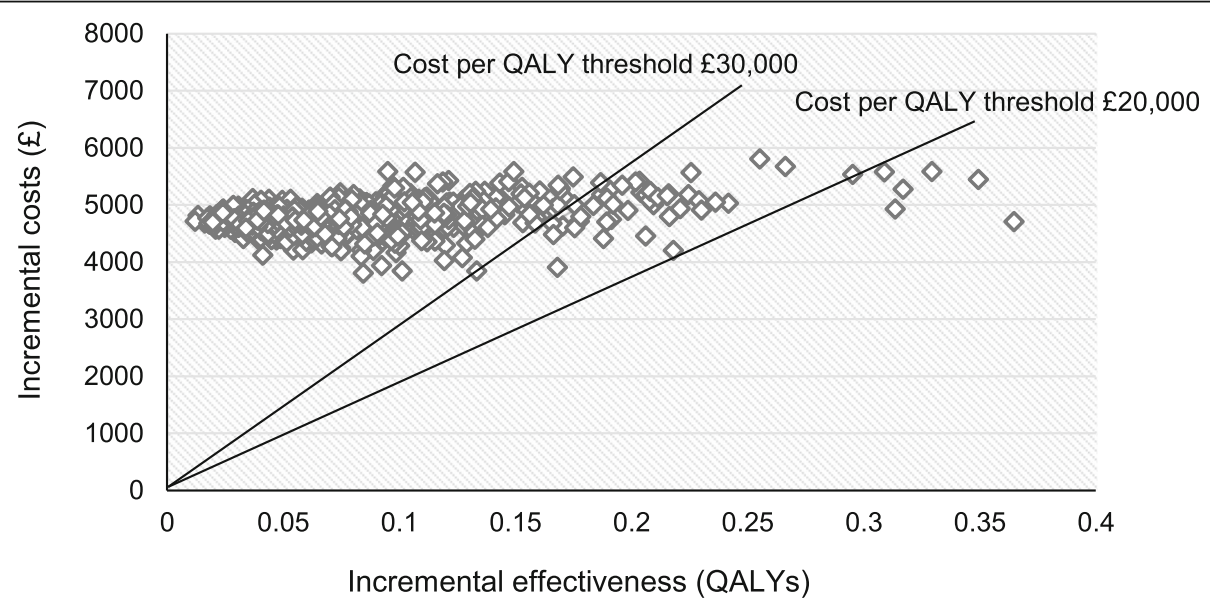

Fig. 2 Probabilistic sensitivity results presented as scatter plot (cost-effectiveness plane), all prices in $£ 2015 / 16$ 
Table 7 One-way sensitivity analysis for different costs of annual health checks and impact on ICER and probability of cost-

effectiveness, all prices in $£ 2015 / 16$, per person

\begin{tabular}{|c|c|c|}
\hline $\begin{array}{l}\text { Cost of the } \\
\text { intervention }\end{array}$ & $\begin{array}{l}\text { Mean ICER } \\
(95 \% \mathrm{Cl})\end{array}$ & $\begin{array}{l}\text { Probability of cost-effectiveness at cost } \\
\text { per QALY threshold of } £ 20,000 \\
(£ 30,000)\end{array}$ \\
\hline$£ 50$ & $\begin{array}{l}£ 17,760(£ 17,180 \\
\text { to } £ 27,110)\end{array}$ & $70.1 \%$ (88.6\%) \\
\hline$£ 75$ & $\begin{array}{l}£ 25,861 \text { ( } £ 24,967 \\
\text { to } £ 40,274)\end{array}$ & $37.1 \%(66.1 \%)$ \\
\hline$£ 100$ & $\begin{array}{l}£ 34,959(£ 33,818 \\
\text { to } £ 53,363)\end{array}$ & $25.5 .9 \%(49.5 \%)$ \\
\hline$£ 150$ & $\begin{array}{l}£ 48,237 \text { ( } £ 46,746 \\
\text { to } £ 72,281)\end{array}$ & $7.1 \%(22.2 \%)$ \\
\hline
\end{tabular}

number of recommendations to improve accessibility of health services beyond the provision of AHCs. It sets out a system-wide responsibility to:

- Support people's communication needs and information preferences; this might include: extending appointment times; contacting persons before appointments; reminding people of appointments; providing written information in an accessible format; using visual aids when explaining procedures or results; supporting the presence of an advocate or someone the person trusts at appointments;

- Increase peoples' awareness of changing health needs due to ageing; this might include providing training for people and their family members in recognising and managing ageing related changes.

Furthermore, the guideline requests the introduction of new roles to make those changes happen. This includes a single lead practitioner as point of contact in each health care setting as well as champions in health care teams who develop specific knowledge and skills working with this population. Those recommendations are - while important and desirable - also ambitious in the current financial climate. The feasibility of their implementation in practice remains to be seen.

\section{Conclusions}

This explorative study is the first to estimate the cost-effectiveness of health checks for people with intellectual disability as they age. It is also the first economic modelling study of health checks for people with intellectual disability at any age. The findings from this study suggest that the current focus by governments on providing yearly health checks for people with ID as they age might not be good value for money. Findings from this study informed recommendations in a guideline by the National Institute for Health and Care Excellence in England. Future research should investigate the impact of AHCs and alternative models of identifying health conditions on: the identification of health conditions such as dementia and mental health disorders; access to secondary care treatment and screening programmes; health-related quality of life improvements; impact on carers and support workers.

\section{Additional file}

Additional file 1: Literature review(s). Details of how the literature was reviewed for this study. Table S1. Rational for including or excluding health conditions (detailed description with references). Summary of evidence for each health condition with conclusions about expected economic impact and feasibility for carrying out modelling. (DOCX $29 \mathrm{~kb}$ )

\section{Abbreviations}

AHC: Annual health checks; CHD: Coronary heart disease; Cl: Confidence interval; ICER: Incremental cost-effectiveness ratio; ID: Intellectual disability; IDS-TILDA: Intellectual Disabilities Supplement to the Irish Longitudinal Study on Aging; NICE: National Institute for Health and Care Excellence;

PSA: Probabilistic sensitivity analysis; QALY: Quality adjusted life years

\section{Acknowledgements}

We are grateful for the support we received from individuals employed by Social Care Institute for Excellence (SCIE) and National Institute for Health and Care Excellence (NICE), who - as part of the development of the guideline - provided important research expertise and inputs as well as managerial and administrative support. In particular we are grateful to the support we received from Jennifer Francis, Beth Anderson, Hannah Roscoe, Zenette Abrahams, Palida Teelucknavan, Ted Baker, Leslie Hayes and Nick Staples. This study was importantly informed by experts with professional or lived experience, many of whom gave much of their time and good will to this work. This includes the following members of the guideline committee: Margaret Lally, Phillipa Russell, Carol Walker, Dawn Wilshire, Emma Killick, Erin Outram, Jan Hoskins, Jenny Anderton, Jenny Garrigan, Jill Foalks, Lisa BirtlesSmith, Patricia Charlesworth, Simon Jones and Stephen Elsmere. In addition we received support on this specific topic from Andre Strydom and Renee Romeo, for which we are also grateful.

\section{Funding}

This work was produced as part of a national guideline for the National Institute for Health and Care Excellence (NICE), which was the sole sponsor of this study. NICE had no role in study design, data collection, or data interpretation. NICE provided technical advice in writing the report; this was restricted to comments concerning the quality of reporting and did not include aspects pertinent to the contents of the study. The corresponding author had full access to all the data in the study and had final responsibility for the decision to submit for publication.

\section{Availability of data and material}

The data analysed during the study are available on request from the National Institute for Health and Care Excellence.

\section{Authors' contributions}

This work was a collaboration led by researchers $(A B, M K)$ at the Personal Social Services Research Unit at the London School of Economics and Political Science working with two committee members (JR, LT) and one advisor (LO) from the National Institute for Health and Care Excellence (NICE) guideline 'Care and support for people growing older with learning disability' and one expert $(\mathrm{CH})$ from the Centre for Disability Research at Lancaster University. AB with experience in economic evaluations in the prevention area in health and social care carried out the economic modelling and led on writing the abstract and paper; LT contributed with his clinical research and health promotion expertise in the area of intellectual 
disability to the modelling, writing of the abstract and paper; JR contributed with her clinical expertise in primary care, intellectual disabilities, mental health and dementia to the modelling, writing of the abstract and paper; $\mathrm{CH}$ contributed with his expertise in public health data and approaches to people with intellectual disabilities to writing the abstract and paper; LO contributed with her expertise as technical advisor for NICE public health guidelines to technical aspects in writing of the abstract and paper; MK provided overarching advice and comments to the overall process contributing in particular to the economic rigor and policy discussion of the study. All authors have read and approved the manuscript.

\section{Ethics approval and consent to participate}

Not applicable.

\section{Consent for publication}

Not applicable.

\section{Competing interests}

The National Institute for Health and Care Excellence (NICE) funded the development of the economic model. LO is an employee of NICE. Her contribution to the paper was restricted to comments concerning the quality of reporting and did not include aspects pertinent to the contents of the study. LO submitted the International Committee of Medical Journal Editors form of disclosure for potential conflicts of interest. JR is Clinical Representative Dementia for the Royal College of General Practitioner, Advisor to Kent Surrey Sussex Academic Health Network and Independent Consultant. All other authors (AB, MK, LT, CH) declared no conflict of interest.

\section{Publisher's Note}

Springer Nature remains neutral with regard to jurisdictional claims in published maps and institutional affiliations.

\section{Author details}

${ }^{1}$ Personal Social Services Research Unit, London School of Economics and Political Science, Houghton Street, London, England WC2A 2AE, UK. ${ }^{2}$ Institute of Nursing \& Health Research, Ulster University, N Ireland, Newtownabbey BT37 OQB, UK. ${ }^{3}$ Royal College of General Practitioners (RCGP), 30 Euston Square, London, England NW1 2FB, UK. ${ }^{4}$ Centre for Disability Research, Division of Health Research, Lancaster University, Lancaster, England LA1 4YG, UK. ${ }^{5}$ National Institute for Health and Care Excellence, 10 Spring Gardens, London, England SW1A 2BU, UK.

\section{Received: 17 October 2018 Accepted: 29 April 2019}

\section{Published online: 07 June 2019}

\section{References}

1. Emerson E, Baines S, Allerton L, Welch V. Health inequalities \& people with learning disabilities in the UK, improving health and lives: learning disabilities observatory; 2012.

2. Evenhuis $\mathrm{H}$, Henderson $\mathrm{CM}$, Beange $\mathrm{H}$, et al. Healthy ageing - adults with intellectual disabilities: physical health issues. Geneva, Switzerland: World Health Organization; 2000.

3. Haveman M, Heller T, Lee L. Etal. Major health risks in aging persons with intellectual disabilities: an overview of recent studies. Journal of Policy and Practice in Intellectual Disabilities. 2010;7:59-69.

4. Emerson E, Hatton C. Health inequalities and people with intellectual disabilities. Cambridge: Cambridge University Press; 2013. https://doi.org/10. 1017/CBO9781139192484.

5. Ali A, Scior K, Ratti V, Strydom A, King M, Hassioitis A. Discrimination and other barriers to accessing health care: perspectives of patients with mild and moderate intellectual disability and their carers. PLoS One. 2013;8: e70855.

6. Bigby C. Ageing with a lifelong disabilities: a guide to practice, program and policy issues for human services professionals. London: Jessica Kingsley Publishers; 2004.

7. McCarron M, Swinburne J, Burke E, McGlinchey E, Carroll R, McCallion P. Patterns of multimorbidity in an older population of persons with an intellectual disability: results from the intellectual disability supplement to the Irish longitudinal study on aging (IDS-TILDA). Res Development Disabilit. 2013:34:521-7
8. Hermans $H$, Evenhuis HM. Multimorbidity in older adults with intellectual disabilities. Res Development Disabilit. 2014;35:776-83.

9. McCarron M, Lawlor BA. Responding to the challenges of ageing and dementia in intellectual disability in Ireland. Aging Ment Health. 2003;7: 413-7.

10. Melville CA, Cooper SA, McGrother CW, Thorp CF, Collacott R. Obesity in adults with Down syndrome: a case-control study. J Intellect Disabil Res. 2005;49:125-33. https://doi.org/10.1111/j.1365-2788.2004.00616.x.

11. Ouellette-Kuntz H, Garcin N, Lewis S, Minnes P, Freeman C, Holden J. Addressing health disparities through promoting equity for individuals with intellectual disabilities. Can J Public Health. 2005;96(2):S8-S22.

12. MacRae S, Brown M, Karatzias T, Taggart L, Truesdale-Kennedy M, Walley R, Sierka A, Northway R, Carey M, Davies M. Diabetes in people with intellectual disabilities: a systematic review of the literature. Res Dev Disabil. 2015; https://doi.org/10.1016/j.ridd.2015.10.003.

13. Srikanth R, Cassidy G, Joiner C, Teeluckdharry S. Osteoporosis in people with intellectual disabilities: a review and a brief study of risk factors for osteoporosis in a community sample of people with intellectual disabilities. J Intellect Disabil Res. 2011;55(1):53-62.

14. Bent $S, M c S h e a ~ L$, Brennan S. The importance of hearing: a review of the literature on hearing loss for older people with learning disabilities. $\mathrm{Br} \mathrm{J}$ Learn Disabil. 2015;43(4):277-84.

15. Bowers B, Webber R, Bigby $C$. Health issues of older people with intellectual disabilities in group homes. J Intellect Develop Disabil. 2014;39(3):261-9.

16. Cooper SA, Morrison J, Allan LM, et al. Practice nurse health checks for adults with intellectual disabilities: a cluster-design, randomised controlled trial. Lancet Psychiatry. 2014;1:511-21.

17. McCarron M, Buke E, Clearly E, Carroll R, McGlincey E, McCallion P. Changes in physical and Behavioural health of with an intellectual disabilities ageing. In: Burke E, McCallion P, McCarron M, editors. Advancing years, different challenges: wave 2 IDS-TILDA, findings on the ageing of people with and intellectual disabilities. Dublin: School of Nursing and Midwifery, the University of Dublin, Trinity College; 2014.

18. O'Leary L, Cooper SA, Hughes-McCormack L. Early death and causes of death of people with intellectual disabilities: a systematic review. J Appl Res Intellect Disabil. 2018;31(3):325-42.

19. Heslop P, Blair PS, Fleming P, Hoghton M, Marriott A, Russ L. The confidential inquiry into premature deaths of people with intellectual disabilities in the UK: a population-based study. Lancet. 2013;383:889-95.

20. Glover G, Williams R, Heslop P, Oyinlola J, Grey J. Mortality in people with intellectual disabilities in England. J Intellect Disabil Res. 2017;61(1):62-74.

21. Robertson J, Hatton C, Emerson E, Baines S. The impact of health checks for people with intellectual disabilities: an updated systematic review. Res Dev Disabil. 2014;35:2450-62.

22. McConkey T, Taggart L, Kane M. Optimising the uptake of health checks for people with intellectual disabilities. J Intellect Disabil. 2015;19(3):205-14.

23. Buszewicz M, Welch $C$, Horsfall $L$, et al. Assessment of an incentivised scheme to provide annual health checks in primary care for adults with intellectual disabilities: a longitudinal cohort study. Lancet Psychiatry. 2014;1:522-30.

24. NHS England. A summary and overview of the Learning Disability Annual Health Check electronic clinical template. https://www.england.nhs.uk/wpcontent/uploads/2017/05/nat-elec-health-check-ld-clinical-template.pdf. Accessed 28 May 2018.

25. NICE. Care and support of people growing older with learning disabilities. NICE guideline 96. London: National Institute for Health and Care Excellence. https://www.nice.org.uk/guidance/ng96. Accessed 18 July 2018.

26. NICE. Guide to the methods of technology appraisal. London: National Institute for Health and Clinical Excellence, 2013. https://www.nice.org.uk/ process/pmg9/chapter/foreword. Accessed 18 July 2018.

27. NICE. Care and support of people growing older with learning disabilities. NICE guideline 96. Appendix C2: Economic report. London: National Institute for Health and Care Excellence. https://www.nice.org.uk/guidance/ ng96/documents/guideline-appendix-3. Accessed 12 Mar 2019.

28. Carvill S. Sensory impairments, intellectual disabilities and psychiatry. J Intellect Disabil Res. 2001;45(6):467-83.

29. Kerr AM, McCulloch D, Oliver K, et al. Medical needs of people with intellectual disabilities require regular reassessment, and the provision of client- and carer-held reports. J Intellect Disabil Res. 2003;47(2):134-45.

30. National Life Tables, London: Office for National Statistics. https://data.gov. uk/dataset/9d64bac9-76bc-44a4-bf09-24b6a5551958/national-life-tables. Accessed 18 July 2018. 
31. Pharoah PD, Sewell B, Fitzsimmons D, et al. Cost effectiveness of the NHS breast screening programme: life table model. BMJ. 2013;346:f2618.

32. Cancer Research UK (2014) The twenty most common cancers 2014, number of new cases UK. http://www.cancerresearchuk.org/sites/default/files/cstreamnode/inc_20common_persons_114.pdf. Accessed 17 May 2017.

33. Tancredi M, Rosengren A, Svensson AM, et al. Excess mortality among persons with type 2 diabetes. N Engl J Med. 2015;373(18):1720-32.

34. Lee S, Shafe AC, Cowie MR. UK stroke incidence, mortality and cardiovascular risk management 1999-2008: time-trend analysis from the general practice Research database. BMJ Open. 2011;1(2):e000269.

35. Sculpher M. The use of probabilistic sensitivity analysis for decision making: the example of drug-eluting stents. Presentation, seminar at Havard Clinical Research Institute. 2004;(17 August 2004).

36. Personal Social Services Research Unit. Unit costs of health and social care 2016. https://www.pssru.ac.uk/project-pages/unit-costs/unit-costs-2016/. Accessed 17 July 2018

37. Lovibond K, Jowett S, Barton P, et al. Cost-effectiveness of options for the diagnosis of high blood pressure in primary care: a modelling study. Lancet. 2011;378:1219-30.

38. Clarke PM, Gray AM, Briggs A, et al. Cost-utility analyses of intensive blood glucose and tight blood pressure control in type 2 diabetes (UKPDS 72). Diabetologia. 2005;48:868-77.

39. Tappenden P, Chilcott J, Eggington S, et al. Option appraisal of population-based colorectal cancer screening programmes in England. Gut. 2007;56(5):677-84.

40. Department of Health. National Schedule for Reference Costs 2015-16 https://www.gov.uk/government/publications/nhs-reference-costs-2015-to2016. Accessed 17 July 2018

41. Laudicella M, Walsh B, Burns E, Smith PC. Cost of care for cancer patients in England: evidence from population-based patient-level data. Br J Cancer 2016;114(11):1286-92.

42. National Institute for Health and Care Excellence, Osteoporosis: assessing the risk of fragility fracture, clinical guideline [CG146], Published date August 2012, Last updated February 2017, https://www.nice.org.uk/guidance/cg146; Last accessed 26 September 2017.

43. National Institute for Health and Care Excellence,Alendronate, etidronate, risedronate, raloxifene and strontium ranelate for the primary prevention of osteoporotic fragility fractures in postmenopausal women, Technology appraisal guidance [TA160], Published date 27 October, Last updated 09 August 2017, https://www.nice.org.uk/guidance/ta160/chapter/3-Thetechnologies; Last accessed 26 September 2017.

44. Leal J, Gray AM, Prieto-Alhambra D, et al. The REFReSH study group, impact of hip fracture on hospital care costs: a population-based study. Osteoporos Int. 2016;27:549-58.

45. Department of Health, general Ophtalmic services: NHS sight test fee, increases to NHS optical voucher values, payments for continuing education and training and pre-registration supervisors grant, 22nd March 2016. https://www.gov.uk/government/publications/general-ophthalmicservice-fees-and-voucher-values-from-april-2019. Accessed 4 May 2019.

46. Burr JM, Mowatt $G$, Hernández R, et al. The clinical effectiveness and costeffectiveness of screening for open angle glaucoma: a systematic review and economic evaluation. Health Technol Assess. 2007;11(41).

47. Frampton G, Harris $\mathrm{P}$, Cooper $\mathrm{K}$, et al. The clinical effectiveness and cost-effectiveness of second-eye cataract surgery: a systematic review and economic evaluation. Health Technol Assess. 2014;18:1-205 v-vi.

48. Clegg A, Loveman E, Gospodarevskaya E, et al. The safety and effectiveness of different methods of ear wax removal: a systematic review and economic evaluation. Health Technol Assess. 2010;14(28)

49. NHS 2017 to 2019 National Tariff: Non mandatory currencies and prices. https://view.officeapps.live.com/op/view.aspx?src= https\%3A\%2F\%2Fimprovement.nhs.uk\%2Fdocuments\%2F605\%2FNonmandatory_prices_2017-19_DoGZzll.xlsx. Accessed 29 May 2018.

50. Lennox N, Bain C, Rey-Conde T, et al. Effects of a comprehensive health assessment programme for Australian adults with intellectual disabilities: a cluster randomized trial. Int J Epidemiol. 2007;36:139-46.

51. Lennox N, Ware R, Bain C, et al. Effects of health screening for adults with intellectual disabilities: a pooled analysis. Br J Gen Pract. 2011;61:193-6.

52. Hewitson P, Ward AM, Heneghan C, et al. Primary care endorsement letter and a patient leaflet to improve participation in colorectal cancer screening: results of a factorial randomised trial. Br J Cancer. 2011;105: 475-80.
53. Gardner MP, Adams A, Jeffreys M. Interventions to increase the uptake of mammography amongst low income women: a systematic review and meta-analysis. PLoS One. 2013;8:e55574.

54. Moran AE, Odden MC, Thanataveerat A, et al. Cost-effectiveness of hypertension therapy according to 2014 guidelines. N Engl J Med. 2015; 372(5):447-55.

55. Straus SE, Majumdar SR, McAlister FA. New evidence for stroke prevention: scientific review. Jama. 2002;288(11):1388-95.

56. Padwal R, Straus SE, McAlister FA. Cardiovascular risk factors and their effects on the decision to treat hypertension: evidence based review. BMJ. 2001;322:977-80.

57. Scholefield JH, Moss S, Sufi F, Mangham CM, Hardcastle JD. Effect of faecal occult blood screening on mortality from colorectal cancer: results from a randomised controlled trial. Gut. 2002;50:840-4.

58. Raine R, Duffy SW, Wardle J, et al. Impact of general practice endorsement on the social gradient in uptake in bowel cancer screening. $\mathrm{Br} J$ Cancer. 2016;114:321-6.

59. Logan RF, Patnick J, Nickerson C, et al. Outcomes of the bowel Cancer screening Programme (BCSP) in England after the first 1 million tests. Gut. 2011;61(10):1439-46.

60. Shepstone L. The SCOOP study - do we now have a rationale to screen for osteoporosis? National Osteoporosis Conference, 7 November 2016, Norwich CTU: University of East Anglia; 2016.

61. Okeke CO, Quigley HA, Jampel HD, et al. Adherence with topical glaucoma medication monitored electronically the Travatan dosing aid study. Ophthalmology. 2009;116:191-9.

62. Morris AE, Lutman ME, Cook AJ, Turner D. An economic evaluation of screening 60- to 70-year-old adults for hearing loss. J Public Health (Oxf). 35(1):139-46.

63. Sinclair N, Littenberg B, Geller B, Muss H. Accuracy of screening mammography in older women. AJR Am J Roentgenol. 2011;197(5):1268-73.

64. Dyer MT, Goldsmith KA, Sharples LS, Buxton MJ. A review of health utilities using the EQ-5D in studies of cardiovascular disease. Health Qual Life Outcomes. 2010:8:13.

65. Whyte S, Chilcott J, Halloran S. Reappraisal of the options for colorectal cancer screening in England. Color Dis. 2012;14:e547-61.

66. Tappenden P, Chilcott J, Eggington S, et al. Option appraisal of populationbased colorectal cancer screening programmes in England. Gut. 2007;56: 677-84.

67. Briggs A, Sculpher M, Claxton K. Chapter 4: making decision models probabilistic. In: decision modelling for health economic evaluation. Oxford: Oxford University Press; 2006. p. 77-120.

68. Russell AM, O'Dwyer JL, Bryant LD, House AO, Birtwistle JC, Meer S, et al. The feasibility of using the EQ-5D-3L with adults with mild to moderate learning disabilities within a randomized control trial: a qualitative evaluation. Pilot Feasibility Stud. 2018;4(1):164.

69. Riemsma RP, Forbes CA, Glanville JM, Eastwood AJ, Kleijnen J. General health status measures for people with cognitive impairment: learning disability and acquired brain injury. Health Technol Assess. 2001;5.

70. Williams V, Battleday S. Where do you want to go next? Bristol: Norah Fry Research Centre, University of Bristol; 2007.

71. Romeo R, Knapp M, Morrison J, et al. Cost estimation of a health-check intervention for adults with intellectual disabilities in the UK. J Intellect Disabil Res. 2009;53:426-39.

72. Carey IM, Hosking FJ, Harris T, et al. Do health checks for adults with intellectual disabilities reduce emergency hospital admissions? Evaluation of a natural experiment. J Epidemiol Community Health. 2017;71:52-8.

73. Strydom A, Romeo R, Perez-Achiaga N, et al. Service use and cost of mental disorder in older adults with intellectual disabilities. Br J Psychiatry. 2010;196: 133-8.

74. Heslop P, Read S, Dunwoodie Stirton F. The hospital provision of reasonable adjustments for people with learning disabilities: findings from freedom of information requests. Br J Learn Disabil. 2018;46(4):258-67.

75. Tuffrey-Wijne I, Goulding L, Giatras N, Abraham E, Gillard S, White S, et al. The barriers to and enablers of providing reasonably adjusted health services to people with intellectual disabilities in acute hospitals: evidence from a mixed-methods study. BMJ Open. 2014;4(4):e004606.

76. Axmon A, Bjorkman M, Ahlstrom G. Hospital readmissions among older people with intellectual disability in comparison with the general population. J Intellect Disabil Res. 2019. https://doi.org/10. 1111/jir.12601. 
77. Alborz A, McNally R, Glendinning C. Access to health care for people with learning disabilities in the UK: mapping the issues and reviewing the evidence. J Health Serv Res Policy. 2005;10:173-82.

78. Osborn DPJ, Horsfall L, Hassiotis A, et al. Access to cancer screening in people with learning disabilities in the UK: cohort study in the health improvement network, a primary care research database. PLoS One. 2012;7: e43841

79. Heller T, Sorenson A. Promoting healthy ageing in adults with developmental disabilities. Dev Disabil Res Rev. 2013;18:22-30.

80. Davies N, Duff M. Breast screening for older women with intellectual disabilities living in community group homes. J Intellect Disabil Res. 2001:45: 253-7.

81. Mclifatrick S, Taggart L, Truesdale-Kennedy M. Supporting women with intellectual disabilities to access breast cancer screening: a healthcare professional perspective. Eur J Cancer Care. 2011;20:412-20.

82. Wilkinson JE, Lauer E, Freud KM, Rosen AK. Determinants of mammography in women with intellectual disabilities. J Am Board Fam Med. 2011;24(6): 693-703.

83. Goodyear-Smith F. Government's plans for universal health checks for people aged 40-75: no certainty that they'll do more good than harm. BMJ. 2013;347:5-5.

84. Mountain GA. Social connectedness in older people: who is responsible? Lancet Public Health. 2018.

85. Government Equalities Office and Equality and Human Rights Commission Equality Act 2010: guidance https://www.gov.uk/guidance/equality-act2010-guidance. Accessed 17 July 2018.

86. United Nations Human Rights, Office of the High Commissioner, Convention of the Rights of People with Disabilities https://www.ohchr.org/ EN/HRBodies/CRPD/Pages/CRPDIndex.aspx. Accessed 17 July 2018.

87. Strydom A, Hassiotis A, Livingston G. Mental health and social care needs of older people with intellectual disabilities. J Appl Res Intellect Disabil. 2005; 18:229-35.

Ready to submit your research? Choose BMC and benefit from:

- fast, convenient online submission

- thorough peer review by experienced researchers in your field

- rapid publication on acceptance

- support for research data, including large and complex data types

- gold Open Access which fosters wider collaboration and increased citations

- maximum visibility for your research: over $100 \mathrm{M}$ website views per year

At BMC, research is always in progress.

Learn more biomedcentral.com/submissions 